\title{
Movable Genetic Elements and Antibiotic Resistance in Enterococci
}

\author{
D. B. Clewell 1,2
}

\begin{abstract}
The enterococci possess genetic elements able to move from one strain to another via conjugation. Certain enterococcal plasmids exhibit a broad host range among gram-positive bacteria, but only when matings are performed on solid surfaces. Other plasmids are more specific to enterococci, transfer efficiently in broth, and encode a response to recipient-produced sex pheromones. Transmissible nonplasmid elements, the conjugative transposons, are widespread among the enterococci and determine their own fertility properties. Drug resistance, hemolysin, and bacteriocin determinants are commonly found on the various transmissible enterococcal elements. Examples of the different systems are discussed in this review.
\end{abstract}

The association of antibiotic resistance with plasmid content in enterococci was first noted by Courvalin et al. (1) in 1972 in a strain of Enterococcus (formerly Streptococcus) faecalis (BM6201), and reports showing that erythromycin $(\mathrm{Em})$ and tetracycline $(\mathrm{Tc})$ resistance were encoded by two different plasmids (designated pIP613 and pIP614, respectively) in this strain soon followed (2). In $1974 \mathrm{Jacob}$ and Hobbs (3) reported that plasmid-encoded resistance determinants in Enterococcus faecalis $\mathrm{JH} 1$ could be transferred by conjugation in broth matings. In this case, resistance to erythromycin, tetracycline, kanamycin $(\mathrm{Km})$ and neomycin was encoded on a plasmid designated $\mathrm{pJH} 1$, and a co-resident plasmid, $\mathrm{pJH} 2$, was found to determine hemolysin and bacteriocin activity. About the same time, Tomura et al. (4) reported a relatively high rate of conjugal transfer of an Enterococcus faecalis hemolysin/bacteriocin trait; however, a physical demonstration of plasmid involvement was not conducted. At the time, conjugative transfer was a rather novel phenomenon in gram-positive bacteria; with the exception of a single unconfirmed report nine years earlier in Enterococcus faecalis (5), the only gram-positive organisms in which conjugation was known to occur were the strepto-

\footnotetext{
${ }^{1}$ Department of Biological and Materials Sciences, School of Dentistry, and Department of Microbiology/Immunology, School of Medicine, University of Michigan, Ann Arbor, Michigan 48109, USA.

${ }^{2}$ Molecular Microbiology Unit, 300 North Ingalls Building, University of Michigan, Ann Arbor, Michigan 481030402, USA.
}

mycetes. Today, of course, numerous plasmids, both conjugative and nonconjugative, have been identified in enterococci and characterized to various degrees $(6,7,8)$. Some nonconjugative plasmids such as pAM $\alpha 1$ can be mobilized at high frequency by certain conjugative plasmids $(9,10)$, whereas other nonconjugative plasmids such as pAD2 are mobilized very inefficiently $(11,12,13)$. Chromosomal determinants were also found to be mobilized at low frequencies $(14,15)$.

Enterococci also commonly harbor conjugative transposons, elements able to transfer in the absence of a mobilizing plasmid $(14,16)$. The prototype of such an element is the Tc-resistance transposon Tn916, originally identified in Enterococcus faecalis DS16 (14). Its discovery paralleled studies of a transferable, nonplasmid, multiple-resistance element in Streptococcus pneumoniae (17).

\section{Conjugative Plasmids}

There are two basic types of conjugative transfer in enterococci: i) that which occurs in broth and at relatively high frequencies, and ii) that which occurs only on solid surfaces (e.g. a filter membrane) and at frequencies usually less than $10^{-3}$. Thus far, plasmids which transfer in broth have been found to encode a response to recipient-produced sex pheromones, whereas surface-requiring matings do not appear to involve these compounds $(6,8)$. In the case of conjugative transposition, transfer generally occurs only on surfaces. 
Multiple antibiotic resistance is common among the enterococci, especially among Enterococcus faecalis, and plasmids are ubiquitous in these organisms. After Jacob and Hobbs (3) reported conjugative resistance transfer, additional reports by others soon followed $(3,9,11-26)$. Many examples have involved donor strains also containing a highly transferable hemolysin plasmid $(3,9,11,20,26-33)$, and the extent to which the latter facilitated the mobilization of unlinked resistance determinants has not always been clear. There has been some effort to place resistance plasmids into different incompatibility groups $(24,34)$.

Clinical isolates shown to produce or respond to sex pheromones are much more likely to be resistant to antibiotics than strains that do not exhibit pheromone phenomena (35). Strains bearing hemolysin plasmids, which usually encode a pheromone response (see below), also tend to be resistant to multiple antibiotics, but it is rare for the hemolysin and resistance traits to be linked $(26,36)$. Hemolysin plasmids have probably played a significant role in the mobilization of resistance determinants located on other elements.

The plasmid pAM $\beta 1$, originally identified in Enterococcus faecalis DS5, has a very broad host range and transfers on solid surfaces to most gram-positive species that have been tested $(6,7)$. This $26 \mathrm{~kb}$ plasmid encodes resistance to erythromycin, although the single erm determinant encodes the so-called MLS phenotype, indicating resistance to macrolides, lincosamides and streptogramin B. The MLS phenotype is common for many erm determinants among gram-positive cocci $(7,37)$. The plasmid has been characterized by LeBlanc and Lee (38), who have mapped positions of erm, a transfer-related region, and a replication region. It was also found that certain regions tend to delete specifically, when the plasmid is introduced into Streptococcus sanguis (39) or Bacillus subtilis (40).

The erm determinant, which has recently been sequenced (41) and which expresses in Escherichia coli, has been utilized in the construction of various Escherichia coli-streptococcal/enterococcal shuttle vectors such as pVA838 $(42,43)$. Recently, Trieu-Cuot et al. $(44,45)$ have constructed shuttle plasmids utilizing components of pAM $31, p B R 322$ and RK2, and have observed conjugative transfer from Escherichia coli to several species of gram-positive bacteria and from Enterococcus faecalis to Escherichia coli.

Other Enterococcus faecalis plasmids, such as pAM81 and pAM490 (46), also exhibit a broad host range among gram-positive organisms and probably have much in common with a number of plasmids that have been identified in various streptococcal species (7). These plasmids tend to be similar in size and usually determine erythromycin resistance; they sometimes encode additional resistances. One such plasmid, pIP501 (47), originally from Streptococcus agalactiae, is easily acquired by enterococci and has been significantly characterized $(48,49,50)$.

\section{Plasmids that Respond to Sex Pheromones}

Over one-third of clinical isolates of Enterococcus faecalis exhibit a clumping response when exposed to culture filtrates of plasmid-free strains $(35,36)$. The clumping-inducing agent was shown to correspond to a sex pheromone that induced a mating response by cells harboring certain conjugative plasmids $(35,51)$. Thus, when a plasmid-bearing donor culture is mixed in broth with potential recipient cells, the "clumping" that results represents the formation of large mating aggregates. The induction requires 30 to 40 minutes, and results in the synthesis of several surface proteins collectively referred to as "aggregation substance" $(30,52$, 53). A wall component referred to as "binding substance", to which aggregation substance is believed to bind, is present on the surface of both donors and recipients (35).

Once the recipient acquires a copy of the plasmid it shuts down the synthesis of the related sex pheromone but continues to synthesize other pheromones that are specific for donors with different plasmids (35). A plasmid-free strain produces at least five different sex pheromones, and it is likely that many more are actually excreted (8). It is not surprising, then, that single strains have been found to harbor multiple pheromone-responding plasmids (10, 54). If a strain harboring more than one plasmid is exposed to a pheromone specific to only one of the plasmids, then only the related plasmid is induced to transfer (53). Table 1 lists the known pheromone-responding plasmids along with some of their properties. It is noted that Enterococcus faecalis strains DS5 and $\mathrm{HH} 22$ each harbor three different pheromone-responding plasmids.

Induction results in the appearance of immunologically unique surface proteins with sizes ranging from 52,000 to 190,000 daltons $(\mathrm{Da})(52-$ 55; K. E. Weaver and D. B. Clewell, unpublished data). In the case of pAD1, these proteins are referred to as $\mathrm{AD} 52, \mathrm{AD} 74, \mathrm{AD} 130, \mathrm{AD} 153$ and AD157; the dominant protein is AD74. Although the designations were originally intended to reflect the relative sizes, recent data have 
Table 1: Plasmids known to encode a pheromone response.

\begin{tabular}{|c|c|c|c|c|c|}
\hline Plasmid & $\begin{array}{l}\text { Size } \\
(k b)\end{array}$ & $\begin{array}{l}\text { Original } \\
\text { host }\end{array}$ & $\begin{array}{l}\text { Phenotype } \\
\text { encoded }^{\mathrm{a}}\end{array}$ & $\begin{array}{c}\text { Related } \\
\text { pheromone }\end{array}$ & $\begin{array}{c}\text { Related } \\
\text { reference(s) }\end{array}$ \\
\hline pAD1 & 60 & DS16 & Hly/Bac, Uv & CAD 1 & $(11,13,35)$ \\
\hline pPD1 & 56 & $39-5$ & $\mathrm{BaC}$ & cPD1 & $(30,51)$ \\
\hline pAM373 & 36 & $\mathrm{RC} 73$ & $?$ & $\mathrm{cAM} 373$ & (73) \\
\hline pCF 10 & 54 & SF-7 & $\operatorname{Tc}^{5}(\operatorname{Tn} 925)$ & cCF10 & (71) \\
\hline pAM $\gamma 1$ & 60 & DS5 & Hly/Bac, Uv & cADI & (10) \\
\hline $\mathrm{pAM} \gamma 2$ & -60 & DS5 & $\mathrm{Bac}$ & $\mathrm{cAM} \gamma 2$ & (10) \\
\hline $\mathrm{pAM} \gamma 3$ & $\sim 60$ & DS5 & $?$ & $\mathrm{cAM} \gamma 3$ & $(10)$ \\
\hline pOB1 & 71 & 5952 & Hly/Bac & $\mathrm{cOB1}$ & $(6,28)$ \\
\hline pJH2 & 59 & $\mathrm{JH1}$ & HIy/Bac & $\mathrm{CAD} 1$ & $(6,27)$ \\
\hline pBEM10 & 70 & $\mathrm{HH} 22$ & $\operatorname{Pen}^{\mathrm{r}}, \mathrm{Gm}^{\mathrm{r}}, \mathrm{Km}^{\mathrm{r}}, \mathrm{Tm}^{\mathrm{T}}$ & CADI & $(54)$ \\
\hline pAM 323 & 66 & $\mathrm{HH} 22$ & $E_{m^{r}}$ & cAM323 & (54) \\
\hline pAM 324 & 53 & $\mathrm{HH} 22$ & $\begin{array}{c}\mathrm{Em} \\
?\end{array}$ & cAM324 & (54) \\
\hline
\end{tabular}

${ }^{a}$ Hly, hemolysin; Bac, bacteriocin; Uv, ultraviolet light resistance; Tc ${ }^{T}$, tetracycline resistance; $\mathrm{Pen}^{\mathrm{F}}$, penicillin resistance; $\mathrm{Gm}^{\mathrm{r}}$, gentamicin resistance; $\mathrm{Km}^{\mathrm{r}}$, kanamycin resistance; $\mathrm{Tm}^{\mathrm{r}}$, lobramycin resistance; $\mathrm{Em}^{\mathrm{r}}$, erythromycin resistance.

Table 2: Structures of sex pheromones and some related inhibitors.

\begin{tabular}{lcc}
\hline $\begin{array}{l}\text { Pheromone or inhibitor } \\
\text { (molecular weight) }\end{array}$ & Peptide structure & Reference \\
\hline cPD1 (912) & H-Phe-Leu-Val-Met-Phe-Leu-Ser-Gly-OH & $(59)$ \\
cAD1 (818) & H-Lcu-Phe-Ser-Leu-Val-Lcu-Ala-Gly-OH & $(60)$ \\
CAM373(733) & H-Ala-Ile-Phe-Ile-Lcu-Ala-Ser-OH & $(61)$ \\
cCF10 (789) & H-Lcu-Val-Thr-Leu-Val-Phe-Val-OH & $(62)$ \\
iPD1 (828) & H-Ala-Leu-Ile-Leu-Thr-Lcu-Val-Ser-OH & $(63)$ \\
iAD1 (846) & H-Leu-Phe-Val-Val-Thr-Leu-Val-Gly-OH & $(64)$ \\
\hline
\end{tabular}

shown that AD153 and AD157 are larger than originally thought; they are closer to 170,000 and $190,000 \mathrm{Da}$, respectively (K. E. Weaver and D. B. Clewell, unpublished data). In the case of pPD1, the dominant protein is designated PD78, and is probably analogous to pAD1's AD74. A similar analogy may occur with the SA73 protein of pCF10 (52).

Wirth and colleagues $(56,57)$ isolated AD74 and raised polyclonal antibodies against it. The antiserum was used in immunogold labeling experiments to observe by electron microscopy a dense layer of "hairs" on the surface of induced cells. The distribution of hairs, after a relatively short induction time $(<40 \mathrm{~min})$, was uneven and appeared to occur only on "old wall". That is, wall synthesized during exposure to pheromone (cAD1) appeared not to give rise to aggregation substance. The purpose of the uneven distribution is not clear, but it might serve as a basis for dissociation of donor and recipient cells after mating. That is, absence of hairs on newly synthesized wall would mean that cell division within a mating aggregate could lead to cells that could escape.
I. Nakayama et al. (to be published) have also purified and characterized AD74 as well as PD78. Antiserum raised against PD78 was able to block aggregation of induced pPD1-containing cells. They also performed amino-terminal analyses of both proteins and found them to be significantly different. This is consistent with observations showing that the two proteins were immunologically distinct (53).

Aggregation of induced cells requires the presence of divalent cations such as $\mathrm{Mg}^{++}$, as well as phosphate ions (30). There is evidence that binding substance probably has a lipoteichoic acid component, since low concentrations ( 0.1 to $1.0 \mu \mathrm{g} / \mathrm{ml}$ ) of lipoteichoic acid were able to block aggregation (53). In this regard it is noteworthy that lipoteichoic acid corresponds to the Lancefield group D antigen of Enterococcus faecalis (58).

Table 2 lists the structures of four sex pheromones (CPD1, CAD1, CAM373 and CCF10) that have been characterized by Suzuki and collaborators (59-62). They are all very hydrophobic octa- or hepta-peptides, and each contains one 
hydroxyamino acid residue, which conceivably could be modified as part of the plasmid-determined shutdown process. In addition, the structure of two inhibitor peptides, iPD1 and IAD1 $(63,64)$, is shown. The latter are competitive inhibitors that are excreted by donors containing pPD1 or pAD1, respectively. The role of the inhibitors is not clear; however, they probably serve to prevent self-induction by low levels of endogenous pheromone or by different pheromones with low levels of cross-reacting activity for the plasmid-specific pheromone receptor site. The iAD1 peptide is $50 \%$ homologous with its corresponding pheromone, cAD1, whereas iPD 1 and CPD1 are only $25 \%$ homologous. Interestingly, iPD1 and $\mathrm{AAD} 1$ have three adjacent residues in common, and the heptapeptide $\mathrm{CCF} 10$ has four adjacent residues in common with iAD1.

Synthetic sex pheromone and inhibitor peptides were found to have full activity and exhibited strong specificity for the related plasmid system. The pheromones are active at concentrations as low as $5 \times 10^{-11} \mathrm{M}(59-62)$, and studies with $\mathrm{c}$ CF10 (62) showed that a donor cell may sense as few as one or two molecules. Synthetic hybrids corresponding to $\mathrm{CPD} 1$ on the amino-terminal half and CAD1 on the carboxy-terminal half exhibited $10 \%$ of the activity of CPD1 but had no cAD1 activity (65). The reverse was true for the converse experiment, with $1 \%$ of the activity of cAD1 and no cPD1 activity. The specificity of the peptide is therefore determined by the amino-terminal sequences.

There is evidence that the structural determinant for iAD1 is located on pAD1, in that when the plasmid was introduced into a strain not exhibiting a cAD1 pheromone system (e.g. Enterococcus faecium 9790), iAD1 was excreted (66). In addition, recent studies (D. B. Clewell, F. Y. An and L. Pontius; to be published) have revealed the nucleotide sequence of iAD1 on pAD1. The genomic sequence shows what is probably a 22 amino acid precursor with the final eight residues at the carboxy-terminus corresponding to iAD1. Efforts to clone pheromone genes from the Enterococcus faecalis chromosome are ongoing but have thus far been difficult due to hybridization of probes to multiple regions.

Genetic analyses have been conducted on pAD1 and pCF10 using transposon mutagenesis. Youngman (67) has developed several temperature-sensitive plasmid-transposon ( $\mathrm{Tn} 917)$ delivery systems which have been particularly useful. It has been possible to generate mutants defective in various aspects of the mating process $(55,68,69)$. In the case of pAD1 (Figure 1), mutants have been obtained that are defective in the ability to aggregate (region F), and in these cases production of certain surface proteins is usually affected. Variants of this type usually transfer plasmid DNA if matings are performed on filter membranes. Other mutants are defective in the ability to transfer DNA (region $G$ and $\mathrm{H}$ ), but are normal with regard to aggregation. In addition, there are mutants that neither aggregate nor transfer (region E); these appear to involve a positive regulator necessary for expression of multiple transfer determinants. Tn917-lac transcriptional fusions within this area of pAD1 result in derivatives that can be induced to produce beta galactosidase upon exposure to cAD1 $(55,70)$.

There are also at least two determinants involved in negative regulation; insertions into these regions, $\operatorname{tra} A$ and $\operatorname{tr} a B$, result in constitutive expression of transfer functions and constitutive clumping (68). There is evidence that the tra $A$ product negatively regulates expression of region $E$, and recent data relating to tra $B$ suggest its product is involved in the shutdown of endogenous cAD1 production (K. E. Weaver and D. B. Clewell, to be published). Region $C$, as well as tra $A$, may be involved in sensing or transducing the pheromone signal $(55,70 ;$ K. E. Weaver and D. B. Clewell, to be published). A more in-depth account of the related genetic analyses is given in a recent review by Clewell and Weaver (8) as well as in References 55 and 70.

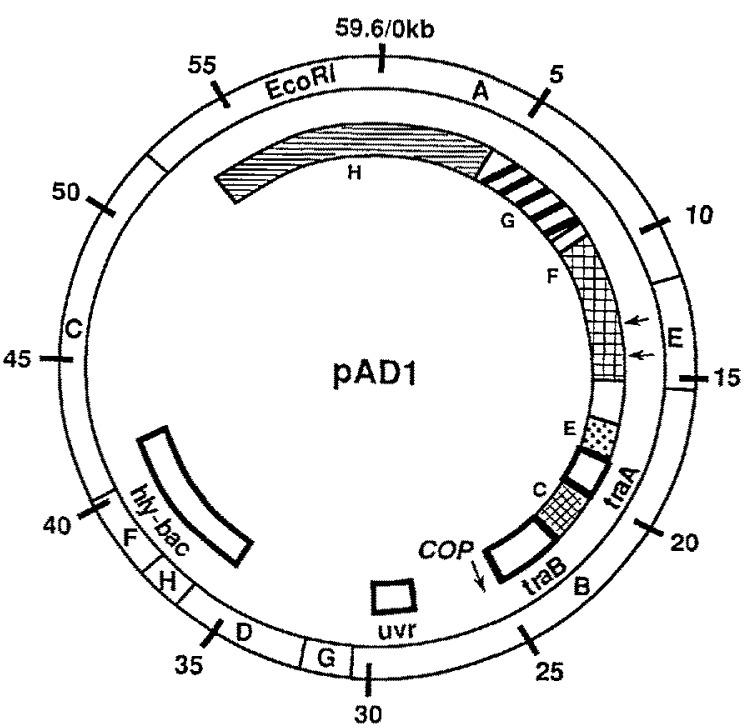

Figure 1: Physical and functional map of pAD1. Regions important for transfer are indicated as shaded or open boxes on the interior of the map and labeled $\operatorname{traA}, \operatorname{tr} a B$, and $C$ through $H$. Regions $h l y-b a c, u v r$ and cop represent genes for hemolysin-bacteriocin, ultraviolet light resistance, and copy number (plasmid), respectively. EcoR 1 fragments are labeled within the outer circle. 
Analyses of pCF10 (71) have revealed some similarities to pAD1 in that there is evidence for both negative and positive regulation (72). In this case, two positive regulator loci designated R130 and R150 have been reported to independently affect surface exclusion and aggregation, respectively. It will be interesting to compare pCF10 and pAD1 as more information becomes available.

It is surprising that in the 11 years since sex pheromone-induced plasmid transfer was discovered in Enterococcus faecalis, this phenomenon has still not been identified in other species of bacteria. Interestingly, a substance similar to the pheromone cAM373 is produced by practically all strains of Staphylococcus aureus and about $15 \%$ of Streptococcus sanguis strains (73); however, there is no evidence that the substance serves as a pheromone in these species.

It has been speculated (74) that the pheromone peptides excreted by plasmid-free strains of Enterococcus faecalis may actually have other functions. It is conceivable that the peptides preceeded the plasmids, and the latter evolved in such a way as to take advantage of these substances as mating signals. If this is true it raises the question of what other roles these compounds might play. Recently, it has been reported that some of these peptides exhibit potent neutrophil chemotaxis activity $(75,76)$. The phenomenon relates, at least in part, to receptors that also recognize f-Met-Leu-Phe. The fact that certain mammalian leukocytes appear to recognize such compounds as CPD1 and cAM373 raises the possibility that these substances could influence the course of a related bacterial infection by enhancing or perhaps modifying the host response. Conceivably, some peptides could act to competitively inhibit the activity of certain chemotactic factors; such compounds might then be considered virulence factors.

\section{An Amplifiable tet Nonconjugative R-Plasmid}

The nonconjugative $9.3 \mathrm{~kb}$ plasmid $\mathrm{pAM} \alpha 1$ bearing tet was originally identified in Enterococcus faecalis strain DS5 and was co-resident with the four conjugative plasmids pAM 1 , pAM21, pAM22 and pAM23 $(9,10,77,78)$. It could be mobilized readily by any of the four conjugative plasmids, and it was possible to generate transconjugants that harbored only pAM $\alpha 1$ (9). When cells harboring pAM $\alpha 1$ were grown in the presence of tetracycline for a number of generations, an increased level of resistance could be detected, and this could be cor- related with a reversible generation of tandem repeats of a $4.1 \mathrm{~kb}$ segment containing tet $(78,79$, $80)$. In addition, cells grown in the absence of tetracycline gave rise to tetracycline-sensitive derivatives with a $4.1 \mathrm{~kb}$ deletion. The $4.1 \mathrm{~kb}$ segment is flanked by two directly repeated 380 base pair sequences designated RS1 (recombination sequence), which are presumed to facilitate the phenomenon (80). Both amplification and deletion failed to occur in a recombination deficient ( $\mathrm{Rec}^{-}$) enterococcal host, and models based on homologous recombination between the direct repeats have been suggested $(80,81)$. This type of resistance amplification is also known to occur with certain R-plasmids in gram-negative bacteria (82). In the case of pAM $\alpha 1$, it is interesting that with increased amplification, the mass of plasmid DNA calculated as a percentage of the chromosomal mass does not change (79); this suggests the involvement of a copy number control mechanism sensitive to total plasmid mass.

Perkins and Youngman (83) have reported that pAM $\alpha 1$ is actually a composite of two separable replicons and that the amplifiable segment is actually a replicon, designated $\mathrm{pAM} \alpha 1 \Delta 1$, capable of autonomous replication in Bacillus subtilis. The other component, designated pAM$\alpha 1 \Delta 2$, corresponds to that of tetracycline-sensitive deletion variants in Enterococcus faecalis. When Bacillus subtilis is transformed with pAM $\alpha 1$, tetracycline-resistant transformants appear to have only pAM $\alpha 1 \Delta 1(83,84)$. It is possible that $\mathrm{pAM} \alpha 1 \Delta 1$ is not able to replicate independently in Enterococcus faecalis and that pAM $\alpha 1 \Delta 2$ is not able to replicate in Bacillus subtilis. Interestingly, pAM $\alpha 1 \Delta 1$ has restriction sites showing it to be virtually identical to the similarly sized, tet-containing Bacillus cereus plasmid $\mathrm{pBC} 16$ (85). Plasmids with high similarity have been found in other species of Bacillus (86), and there is a close relationship with the Staphylococcus aureus plasmid pUB110 (87), which differs only in having a Km-resistance determinant rather than tet. In addition, the Enterococcus faecalis plasmid $\mathrm{pJH} 1(88)$ and the $B a$ cillus subtilis Marburg 168 chromosome (89) have been shown to contain integrated pAM$\alpha 1 \Delta 1$-like elements. The tet of pAM $\alpha 1$ has been sequenced and found to encode a 458 amino acid protein (90). Burdett et al. (91) have categorized this particular determinant as tetL.

\section{Conjugative Transposons}

The initial identification of a conjugative transposon occurred in Enterococcus faecalis strain DS16 (14). The Iatter is a multiply antibiotic resistant strain originally found to contain two 
plasmids, pAD1 (see above) and pAD2 (11). The latter determines resistance to erythromycin, kanamycin and streptomycin (Sm). The erm determinant is located on what was eventually found to represent $\operatorname{Tn} 917$ (12). A tet determinant was found to be located on the chromosome. When tet was mobilized in mating experiments, most transconjugants were hemolytic, and some were found to be hyperhemolytic. The latter contained a $16 \mathrm{~kb}$ insertion in pAD1 close to the hemolysin determinant. Insertions of a similar size into different sites on pAD1 could be found in other derivatives; some completely inactivated hemolysin expression. It was apparent that tet was located on a $16 \mathrm{~kb}$ transposon that could insert at multiple sites on pAD1; it was designated Tn916.

It was surprising at the time to find that plasmid-free derivatives of DS16 were able to transfer tetracycline resistance in filter matings (14, 92). Transfer required cell-to-cell contact, and insertions occurred at different locations in the recipient chromosome. This type of movement can be viewed as an intercellular transposition event - thus, the term conjugative transposon. Both intracellular and intercellular transposition are $\mathrm{Rec}$-independent.

Similar elements, designated Tn918 (73), Tn920 (54) and $\operatorname{Tn} 925$ (93), all encoding tetracycline resistance, have been identified in different strains of Enterococcus faecalis; and additional elements, also carrying tet $(\operatorname{Tn} 5031, \operatorname{Tn} 5032$ and Tn5033), have been revealed in strains of $E n-$ terococcus faecium (H. Fletcher et al., to be published). Conjugative transposons have been found primarily on the bacterial chromosome, although $\operatorname{Tn} 925$ was originally found on pCF10.

Tn916 has a very broad host range and will transfer into numerous gram-positive genera (16). Chromosome-borne conjugative transposons have also been found in gram-positive species such as Streptococcus sanguis (94), Streptococcus pneumoniae $(95,96)$, Streptococcus agalactiae $(97,98)$, Streptococcus pyogenes (99) and Clostridium difficile (100). In some cases these nonplasmid transferable elements are much larger (more than $60 \mathrm{~kb}$ ) and carry multiple resistances. All include a Tc-resistance determinant of the tet $M$ variety (91), and, in all cases tested, there appears to be strong homology with Tn916 (16). Like Tn916, the transposon $\mathrm{Tn} 1545$ (determines resistance to tetracycline, erythromycin and kanamycin) from Streptococcus pneumoniae has been the subject of detailed analyses $(95,101,102)$. The tet determinant of $\operatorname{Tn} 1545$ has been sequenced (103), and recent analysis of the tet of Tn916 show it to be extremely similar (Y.Su and D. B. Clewell, unpublished data). The tet $M$ protein is estimated to have a size of 72,500 daltons.
Enterococcus faecalis transconjugants with Tn916 inserted at different sites on the chromosome donated the element at frequencies of $10^{-9}$ to $10^{-5}$ per donor, depending on the strain (92). The differences in frequency are most likely influenced by sequences outside the transposon. There is a positive correlation between conjugative donor potential and transposition to a subsequently introduced plasmid. For example, two strains whose transfer potential differed by a factor of 100 also exhibited a 100 -fold difference in the ability to generate inserts into pAD1 (92). Tn916 has been cloned in Escherichia coli on plasmid vectors where it has been mapped and studied genetically. In the Escherichia coli background there is a strong tendency for the transposon to excise, giving rise to tetracycline-sensitive variants at a relatively high frequency under nonselective conditions (104). It was proposed $(92,104)$ that an excision giving rise to a nonreplicating circular intermediate is the first and rate-limiting step in a transposition event, and that its high frequency in the Escherichia coli background reflects an aberrant expression of this step. Indeed, circular intermediates have been isolated in Escherichia coli and found to transform Bacillus subtilis, giving rise to normal insertions in the chromosome (105).

Tn916 can be easily reintroduced into Enterococcus faecalis via protoplast transformation (106) with Escherichia coli plasmid chimeras (107). This leads to an insertion into the enterococcal chromosome. Using Tn5 as an insertional mutagen $(107,108)$ in Escherichia coli, it was possible to generate insertions into numerous sites in Tn916. Some insertions (close to the left end of the transposon) resulted in an inability to excise in Escherichia coli. Such derivatives could not give rise to insertions into the enterococcal chromosome upon protoplast transformation. The ability to excise in Escherichia coli could be complemented in trans when the corresponding DNA was made available on a co-resident plasmid. Other Tn 5 insertions specifically affected the ability to conjugate (108).

The ends of $\operatorname{Tn} 916$ have been sequenced (109, $110)$ and have been found to contain imperfect inverted repeat sequences with identity at 20 of 26 nucleotides. Farther in from the ends, imperfect directly repeated sequences are present, with 24 of 27 nucleotides matching. Within the right terminus is a potential outwardly reading promoter site. The transposon junction regions contain homologous segments, but of a nature not consistent with a direct duplication of the target sequence. Essentially identical sequence termini have been found in the case of Tn1545 (102). On the basis of combined junction data from Tn916 and Tn1545, a novel mechanism has been proposed whereby a transposon-specific 
Eur. J. Clin. Microbiol. Infect Dis.

excisase generates staggered nicks of 5 or 6 base pair (111; M. Caparon et al., to be published) at each nonidentical junction, leading to a circular molecule with heteroduplexes at the recombination sites. It was proposed that resulting mismatches might be rectified by the mismatch repair system of the host or by replication.

\section{Other Transposons}

More conventional (i. e. nonconjugative) transposons have also been found in enterococci. The above-mentioned Tn917 (5.3 kb; carrying erm) was originally identified on the nonconjugative plasmid pAD2 $(12,13)$ and is a member of the Tn3 family of transposons (112). It was discovered on the basis of its ability to transpose to the highly conjugative pAD1. The general structure of the transposon, based on a sequence analysis $(113,114)$, is shown in Figure 2. All open reading frames (ORFs) are such that transcription is from left to right. The erm (MLS) determinant is essentially identical to that of the plasmid pAM77 that originally came from Streptococcus sanguis A1 (115, 116). Horinouchi et al. (116) had previously sequenced the latter and showed that it contained a complex translational attenuation control region for erm expression. This region is also present in Tn917 and corresponds to ORF1. The region corresponding to ORF3 is also present in pAM77, but homology terminates two base pairs beyond the ORF3 stop codon (113); the function of ORF3 is not known. ORF4 corresponds to a resolvase determinant $(\operatorname{tn} p R)$ (112) and exhibits homology with other inpR determinants. The remainder of the transposon was originally reported to consist of two additional ORFs, ORF5 and QRF6 (113); a recent

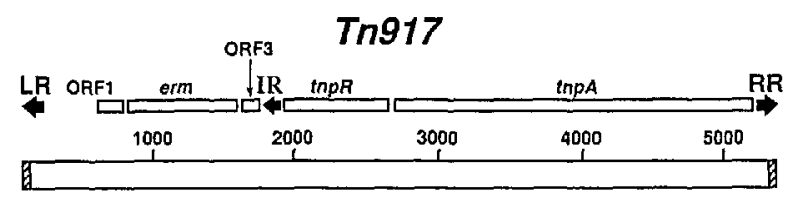

Figure 2: Map of transposon $\mathrm{Tn}$ 917. The five open reading frames (ORFs) are all on the same strand and are transcribed from left to right. ORF2 is indicated as erm (the erythromycin-resistance determinant), whereas ORF4 and ORF5 are indicated as $\operatorname{mpR}$ (resolvase determinant) and inpA (transposase determinant), respectively. The location and orientation of the left, internal and right repeats are indicated as LR, IR and RR, respectively. Although not apparent from the figure, the IR is actually almosi completely within the $3^{\prime}$ end of ORF3. The map represents a revision of that shown in Reference 113; ORF5 and what had been viewed as a separate ORF (ORF6) are now joined together to represent inpA. sequence correction, however, has shown that the two are actually joined to make a single ORF (F. Y. An and D. B. Clewell, unpublished data). The latter exhibits some homology to $\operatorname{tnp} A$ (transposase) of other Tn3-family transposons (117).

Tn917 generates a 5 base pair duplication of target DNA and contains 38 base pair repeats at the termini, typical of Tn3-family elements. It also contains an internal 38 base pair repeat that is inverted with respect to the right end terminus (113). The segment defined by the latter two sequences, which does not include erm, may be capable of transposing on its own, although this has not been directly demonstrated. An analogous situation is known to occur in the case of Tn1721, in which an internal minor transposon designated $\mathrm{Tn} 1722$ is present $(118$, 119). Tn4430, from Bacillus thuringiensis, is an element with no determinants other than those necessary for transposition (120); interestingly, it has significant homology with the corresponding region of $\operatorname{Tn} 917(117,121,122)$.

The internal 38 base pair sequence in $\operatorname{Tn} 917$ is in direct orientation with respect to the left end terminus; and extensions to the right of these two sequences, giving rise to direct repeats of 73 rather than 38 base pairs, provide additional homology (113). Since they flank erm, recombination between the two might lead to deletion or amplification of the resistance determinant. Although erm is inducible to a high level of resistance with erythromycin, it is important to note that some macrolides and lincosamides do not induce (37); in the latter cases, amplification might offer another means of elevating expression.

An especially interesting property of $\mathrm{Tn} 917$ is its ability to undergo enhanced transposition on exposure to erythromycin (12). Both resistance and transposition were inducible at erythromycin concentrations as low as $0.001 \mu \mathrm{g} / \mathrm{ml}$ but not $0.0001 \mu \mathrm{g} / \mathrm{ml}$, suggesting a common or similar regulatory mechanism. Studies showed that this is probably related to transcriptional readthrough from the erm determinant in o the remainder of the transposon (113). The Tn3-family transposon $\mathrm{Tn} 501$, encoding mercury resistance, is another example of an element that can be induced to transpose by the compound to which it encodes resistance $(112,123)$.

Tn917 is extremely similar to $\operatorname{Tn} 551$, an element originally identified on a staphylococcal plasmid (114). Tn551, however, expresses erm constitutively, whereas the erm of $\operatorname{Tn} 917$ is inducible. A Tn917-like transposon (Tn3871) occurs on the enterococcal multiple resistance plasmid pJH1 (124), and very similar elements have been identified in isolates from various humans, chickens and pigs $(125,126)$. These 
data, and the fact that $\operatorname{Tn} 917, \operatorname{Tn} 3871$ and $\operatorname{Tn} 551$ came from isolates in Michigan, London and Japan, respectively, imply that this element is widely disseminated. It is also interesting that a number of Enterococcus faecalis plasmids, including pJH1 and pAD2, have been found to contain $\mathrm{Km}$ - and Sm-resistance determinants adjacent to Tn917-like elements and on a 9-11 $\mathrm{kb}$ DNA segment (126).

As noted earlier, Youngman (67) has developed a number of very useful transposon delivery vectors based on plasmid temperature sensitivity (67); these include various $\mathrm{Tn} 917$ derivatives that can be used for the generation of transcriptional fusions and for cloning purposes. Although developed primarily for Bacillus, the system has been found to work nicely in enterococci, where it can be used to generate both plasmid and chromosomal mutations (127).

It is likely that other resistance transposons will soon be identified in enterococci. The fact that gentamicin-resistance determinants have recently been found on a variety of apparently unrelated plasmids $(128,129)$ strongly suggests the involvement of one or more transpositional elements.

\section{Hemolysin/Bacteriocin}

A significant percentage of clinical isolates of Enterococcus faecalis produce a cytolytic protein that lyses human, rabbit and horse erythrocytes $(6,130$, and see above). A recent study in Japan found that $60 \%$ of Enterococcus faecalis strains associated with parenteral infections were hemolytic, in contrast to $17 \%$ of strains isolated from faecal specimens (36); and hemolysin activity has been shown to contribute to virulence in a mouse model (131).

The Enterococcus faecalis hemolysin also possesses a bacteriocin activity which inhibits a broad range of gram-positive species $(132,133)$. The hemolysin/bacteriocin phenotype is usually encoded by a plasmid, which in the majority of cases is conjugative and determines a pheromone response $(6,36)$. Plasmids such as pAD1 and pAM 21 as well as a number of hemolysin/bacteriocin plasmids from Japanese isolates exhibit almost identical EcoR1 restriction profiles (134). Other studies indicate most belong to the same incompatibility group (32), and many encode a response to the sex pheromone cAD1 $(8,36)$.

The hemolysin/bacteriocin activity is a twocomponent system where one component serves to activate lytic activity possessed by the other (135). The two components are referred to as $\mathrm{A}$ (activator) and L (lytic). When mutants defec- tive in A grow as colonies on blood agar near mutants defective in $L$, a zone of hemolysis is generated on blood plates in a region between the two strains. The activation process therefore can occur extracellularly. The two proteins have been purified from Enterococcus faecalis strain $X-14$ and partially characterized $(136,137)$.

The hemolysin/bacteriocin determinant (hly/ bac) of pAD1 has recently been analyzed by insertional mutagenesis and cloning approaches, and the regions determining the $A$ and $L$ components have been further defined (138). Approximately $8.4 \mathrm{~kb}$ of DNA was necessary for $h l y / b a c$ expression. In addition, the A component was found to be associated with host immunity to the related bacteriocin activity.

It is interesting that hemolysin/bacteriocin plasmids such as pAD1 possess a site (or small region) in or close to the hem/bac determinant which behaves as a hot spot for many conjugative transposons (16). This frequently results in inactivation or hyperexpression of the hemolysin/bacteriocin. In the case of hyperexpression, colonies give rise to zones of hemolysis three to four times the normal diameter on blood agar. In some cases, hyperhemolysis is stimulated by the presence of tetracycline in the blood plates. If tetracycline is not present in these cases, colonies initially appear nonhemolytic; but if the plates are allowed to incubate further for a few days at room temperature, a "wave" of hemolysis may be seen to spread through the plate. Hemolysis around one colony appears to trigger hemolysis of nearby colonies, until all have a hyperhemolytic appearance. The effect of tetracycline may be nonspecific, since a pAD1::Tn916 derivative of this type which also had a Tn917 insertion could be similarly stimulated with either tetracycline or erythromycin (Y. Yagi and C. Gawron-Burke, unpublished data). It is therefore likely that the enhancement of hyperhemolytic expression in these cases arises from a drug-related "stress effect." The basis for hyperhemolytic expression relating to the insertion of conjugative transposons remains unknown. The possible role of an outwardly reading promoter on the transposon has been considered (110). It is important to note that such a phenomenon has never been observed to occur with insertions of the more conventional Tn917, despite the fact that numerous insertions into the pAD1 hem/bac area have been generated.

\section{Concluding Remarks}

Like many other bacteria, the enterococci have a variety of elements that facilitate the intra- 
Eur. J. Clin. Microbiol. Infect Dis.

cellular and intercellular movement of genetic information. The intestinal location of these organisms and their abundance of plasmids and transposons suggests they may serve as a significant reservoir of genetic information available to other gram-positive bacteria in the gut much the way Escherichia coli is sometimes viewed as a reservoir of information for gramnegative bacteria.

The increasing clinical significance of enterococcal infections and related problems of multiple antibiotic resistance emphasizes the importance of conducting further research aimed at elucidating factors associated with colonization and survival of enterococci. The relatively recent acquisition of plasmid-borne resistance to gentamicin $(20,23,128,129)$ and a $\beta$-lactamase-associated penicillin resistance $(128,139$, 140 ) has left vancomycin as one of the few drugs remaining for treating serious infections such as subacute bacterial endocarditis, and the very recently detected plasmid-borne vancomycin resistance in a few clinical isolates is particularly disquieting $(141,142)$.

\section{Acknowledgements}

I would like to thank my colleagues who supplied reprints or preprints of their work which helped to make this review as up-to-date as possible. Work from my laboratory described in this review was supported by USPHS Grants GM33956, AI10318 and DE02731.

\section{References}

1. Courvalin PM, Carlier C, Chabhert YA: Plasmid linked tetracycline and erythromycin resistance in group D Streptococcus. Annales de l'Institut Pasteur 1972, 123: 755-759.

2. Courvalin PM, Carlier C, Croissant O, Blangy D: Identification of two plasmids determining resistance to tetracycline and to erythromycin in group D Streptococcus. Molecular and General Genetics 1974, 132: 181-192.

3. Jacob A, Hobbs SJ: Conjugal transfer of plasmidborne multiple antibiotic resistance in Streptococcus faecalis var. zymogenes. Journal of Bacteriology 1974, 117: $360-372$.

4. Tomura T, Hirano T, Ito T, Yoshioka M: Transmission of bacteriocinogenicity by conjugation in group D streptococci. Japanese Journal of Microbiology 1973, 17: 445-452.

5. Raycroft RE, Zimmerman LN: New mode of genetic transfer in Streptococcus faecalis var. liquefaciens. Journal of Bacteriology 1964, 87; 799-801.

6. Clewell DB: Plasmids, drug resistance, and gene transfer in the genus Streptococcus. Microbiological Reviews 1981, 45: 409-436.
7. Horaud T, Leßouguenec C, Pepper K: Molecular genetics of resistance to macrolides, lincosamides and streptogramin B (MLS) in streptococci. Journal of Antimicrobial Chemotherapy 1985, 16, Supple. ment A: 111-135.

8. Clewell DB, Weaver KE: Sex pheromones and plasmid transfer in Enterococcus faecalis. Plasmid 1989, 21: $175-184$.

9. Dunny GM, Clewell DB: Transmissible toxin themolysin) plasmid in Streptococcus faecalis and its mobilization of a noninfectious drug resistance plasmid. Journal of Bacteriology 1975, 124: 784-790.

10. Clewell DB, Yagi Y, Ike Y, Craig RA, Brown BL, An F: Sex pheromones in Streptococcus faecalis: multiple pheromone systems in strain DS5, similarities of pAD1 and pAM21, and mutants of pAD1 altered in conjugative properties. In: Schlessinger D (ed): Microbiology - 1982. American Sociely for Microbiology, Washington, DC, 1982, p. 97-100.

11. Tomich P, An F, Damle S, Clewell D B: Plasmid related transmissibility and multiple drug resistance in Streptococcus faecalis subsp. zymogenes strain DS16. Antimicrobial Agents and Chemotherapy $1979,15: 828-830$.

12. Tomich P, An F, Clewell DB: Properties of erythromycin-inducible transposon Tn977 in Streptococcus faecalis. Journal of Bacteriology 1980, 141: 13661374.

13. Clewell DB, Tomich PK, Gawron-Burke MC, Franke AE, Yagi Y, An F: Mapping of Sireptococcus faecalis plasmids pAD1 and pAD2 and studies relating to transposition of Tn977. Journal of Bacteriology 1982, 152: 1220-1230.

14. Franke AE, Clewell DB: Evidence for a chromosome-borne resistance transposon in Streplococcus faecalis capable of "conjugal" transfer in the absence of a conjugative plasmid. Journal of Bacteriology 1981,$145 ; 494-502$.

15. Franke A, Dunny G, Brown B, An F, Oliver D, Damle S, Clcwell D: Gene transfer in Sireptococcus faecalis. Evidence for the mobilization of chromosomal determinants by transmissible plasmids. In: Schlessinger D (ed): Microbiology - 1978. American Society for Microbiology, Washington, DC, 1978, p. $45-47$.

16. Clewell DB, Gawron-Burke $C$ : Conjugative transposons and the dissemination of antibiotic resistance in streptococci. Annual Review of Microbiolngy 1986, 40:635-659.

17. Shocmaker NB, Smith MD, Guild WR: DNaseresistant transfer of chromosomal cat and $t e t$ insertions by filter mating in pneumococcus. Plasmid $1980,3: 80-87$.

18. Marder H, Kayser FH: Transferable plasmids mediating multiple-antibiotic resistance in Streptococcus faecalis subsp. liquefaciens. Antimicrobial Agents and Chemotherapy 1977, 12: 261-269.

19. Courvalin PM, Shaw WV, Jacob AE; Plasmidmediated mechanisms of resistance to aminoglycoside-aminocyclitol antibiotics and to chloramphenicol in group D streptococci. Antimicrobial Agents and Chemotherapy 1978, 13: 716-721.

20. Courvalin P, Carlier C, Collat $z$ E: Plasinid-mediated resistance to aminocyclitol antibiotics in group D streptococci. Journal of Bacteriology 1980, 143 : $541-551$.

21. van Embden J, Engel H, van Klingeren B: Drug resistance in group D streptococci of clinical and nonclinical origin: prevalence, transferability, and plasmid properties. Antimicrobial Agents and Chemotherapy 1977, 11: 925-932. 
22. Krogstad DJ, Korfhagen TR, Moellering Jr RC, Wennersten C, Schwartz MN: Plasmid-mediated resistance to antibiotic synergism in enterococci. Journal of Clinical Investigation 1978, 61: 1645-1653.

23. Horodniceanu $T$, Bougueleret $L$, El Solh $N$, Bicth G, Delbos F: High level, plasmid-borne resistance to gentamicin in Sireptococcus faecalis subsp. zymogenes. Antimicrobial Agents and Chemotherapy $1979,16: 686-689$

24. Romero E, Perduca M, Pagani L: Plasmids mediating multiple antibiotic resistance in group D streptococci: prevalence and compatibility characteristics. Microbiologica 1979, 2; 421-424.

25. Engel H, Socdirman N, Rost J, van Leeuwen $W$, yan Embden JDA: Transferability of macrolide, lincosamide, and streptogramin resistances between group A, B, and D streptococci, Streptococcus pneumoniae, and Staphylococcus aureus. Journal of Bacterjology 1980, 142: 407-413,

26. Bondi M, Messi P, Borghi V, Manicardi G: Conjugal plasmids in group $D$ streptococci. Microbiologica 1984, $7: 133-140$.

27. Jacob A, Douglas GI, Hobbs SJ: Self-transferable plasmids determining the hemolysin and bacteriocin of Streprococcus faecalis var. zymogenes. Journal of Bacteriology 1975, 121:863-872.

28. Oliver D, Brown B, Clewell DB: Characterization of plasmids determining hemolysin and bacteriocin production in Streptococcus faecalis. Journal of Bacteriology 1977, 130:948-950.

29. Frazier ML, Zimmerman LN: Genetic loci of hemolysin production in Streptococcus faecalis subsp. zymogenes. Journal of Bacteriology 1977, 130: 10641071.

30. Yagi Y, Kessler RE, Shaw JH, Lopatin DE, An FY, Clewell DB: Plasmid content of Streptococcus faecalis strain 39-5 and identification of a pheromone (cPD1)-induced surface antigen. Journal of General Microbiology 1983, 129: 1207-1215.

31. Borderon $\mathbf{E}$, Bicth $\mathbf{G}$, Horodniceanu $T$ : Genetic and physical studies of Streptococcus faecalis hemolysin plasmids. FEMS Microbiology Letters 1982, 14: 51-55.

32. Colmar I, Horaud T: Enterococcus faecalis hemolysin-bacteriocin plasmids belong to the same incompatibility group. Applied and Environmental Microbiology 1987, 53: 567-570.

33. Siegrist HH, Birch BR, Jacob AE: Detection of a large haemolysin plasmid carrying multiple antibiotic resistance markers in Streptococcus faecalis. Microbial Pathogenesis 1987, 2: 155-158.

34. Messi P, Bondi M, Borghi V, Piccinini L, Manicardi G: $\mathbf{R}$ factors in group D streptococci: classification by compatibility. Microbiologica 1982, 5: 281-284

35. Dunny GM, Craig RA, Carron RL, Clewell DB: Plasmid transfer in Streptococcus faecalis: production of multiple sex pheromones by recipients. Plasmid 1979, 2: 454-465.

36. Ike $\mathbf{Y}$, Hashimoto $\mathbf{H}$, Clewell DL: High incidence of hemolysin production by Enterococcus (Streptococcus) faecalis strains associated with human parenteral infections. Journal of Clinical Microbiology 1987, 25: 1524-1528.

37. Weisblum B: Inducible resistance to macrolides, lincosamides, and streptogramin type-B antibiotics: the resistance phenotype, its biological diversity, and structural elements that regulate cxpression. In: Gene function in prokaryotes. Cold Spring Harbor Laboratory, New York, 1983, p. 91-121.

38. LeBlane DJ, Lee LN: Physical and genetic analyses of streptococcal plasmid pAM $\beta 1$ and cloning of its replication region. Journal of Bacteriology 1984, 157: 445-453.

39. Macrina FL, Keeler Jr CL, Jones KR, Wood PH: Molecular characterization of unique deletion $\mathrm{mu}-$ tants of the streptococcal plasmid, pAM $\beta 1$. Plasmid $1980,4: 8-16$.

40. van der Lelie D, Venema G: Bacillus subtilis generates a major specific deletion in pAMB1. Applied and Environmental Microbiology 1987, 53: 24582463.

41. Martin B, Alloing G, Mejean V, Claverys JP: Constitutive expression of erythromycin resistance mediated by the erm $A M$ determinant of plasmid $p A M B 1$ results from deletion of $5^{\prime}$ leader peptide sequences. Plasmid 1987, 18: 250-253.

42. Macrina FL, Tobian JA, Jones KR, Evans RP, Clewell DB: A cloning vector able to replicate in Escherichia coli and Sireptococcus sanguis. Gene 1982, 19: 345-353.

43. Macrina FL, Evans RP, Tobian JA, Hartley DL, Clewell DB, Jones KR: Novel shutule plasmid vehicles for Escherichia-Streptococcus transgeneric cloning. Gene 1983, 25: 145-150.

44. Trieu-Cuot P, Carlier C, Martin P, Courvalin P: Plasmid transfer by conjugation from Escherichia coli to gram-positive bacteria. FEMS Microbiology Letters 1987, 48: 289-294.

45. Trieu-Cuot $\mathbf{P}$, Carlicr $\mathbf{C}$, Courvalin P: Conjugative plasmid transfer from Enterococcus faecalis to Escherichia coli. Journal of Bacteriology 1988, 170; 4388-4391.

46. Clewell DB, Fizgerald GF, Dempsey L, Pearce LE, An F, White BA, Yagi Y, Gawron-Burke C: Streptococcal conjugation; plasmids, sex pheromones, and conjugative transposons. In: Mergenhagen SE, Rosan B (ed): Molecular basis of oral microbial adhesion. American Society for Microbiology, Washington, DC, 1985, p. 194-203.

47. Horodniceanu $\mathbf{T}$, Bouanchaud $\mathbf{D}$, Biet $\mathbf{G}$, Chabbert Y: $R$ plasmids in Sireptococcus agalactiae (group B). Antimicrobial Agents and Chemotherapy 1976, 10: 795-801.

48. Hershfield V: Plasmids mediating multiple drug resistance in group B Streptococcus: transferability and molecular properties. Plasmid 1979, 2: 137-149.

49. Evans Jr RP, Macrina FL: Streptococcal R plasmid pIP501: endonuclease site map, resistance determinant location, and construction of novel derivatives. Journal of Bacteriology 1983, 154: 1347-1355.

50. Behnke D, Gilmore MS: Location of antibiotic resistance determinants, copy control, and replication functions on the double-selective cloning vector pGB301. Molecular and General Genetics 1981, 184: $115-120$.

51. Dunny GM, Brown B, Clewell DB: Induced cell aggregation and mating in Streplococcus faecalis. Evidence for a bacterial sex pheromone. Proceedings of the National Academy of Sciences of the USA $1978,75: 3479-3483$.

52. Tortorello ML, Dunny GM: Identification of multiple surface antigens associated with the sex pheromone response of Streptococcus faecalis. Journal of Bacteriology 1985, 162:131-137.

53. Ehrenfeld EE, Kessler RE, Clewell DB: Identification of pheromone-induced surface proteins in Streptococcus faecalis and evidence of a role for lipoteichoic acid in formation of mating aggregates. Journal of Bacteriology 1986, 168: 6-12.

54. Murray BE, An F, Clewell DB: Plasmids and pheromone response of the $\beta$-lactamase producer Streptococcus (Enterococcus) faecalis $\mathrm{HH} 22$. Antimicrobial Agents and Chemotherapy 1988, 32: 547551. 
55. Weaver KE, Clewell DB: Regulation of the pAD1 sex pheromone response in Enterococcus faecalis: construction and characterization of lac $Z$ transcriptional fusions in a key control region of the plasmid. Journal of Bacteriology 1988, 4343-4352.

56. Galli D, Wirth $\mathbf{R}$, Wanner $G$ : Identification of aggregation substances of Enterococcus faecalis cells after induction by sex pheromones. An immunological and ultrastructural investigation. Archives of Microbiology 1989, 151: 486-490.

57. Wanner G, Formanck H, Galli D, Wirth R: Loca]ization of aggregation substances of Enterococcus faecalis after induction by sex pheromones. An ultrastructural comparison using immuno labelling, transmission and high resolution scanning electron microscopic techniques. Archives of Microbiology 1989, 151: 491-497.

58. Wicken AJ, Elliott SD, Baddiley J: The identity of streptococcal group D antigen with tcichoic acid. Journal of General Microbiology 1963, 31:231-239.

59. Suzuki A, Mori M, Sakagami $Y$, Isogai A, Fujino M, Kitada C, Craig RA, Clewell D B: Isolation and structure of bacterial sex pheromone cPD1. Science 1984, 226: 849-850.

60. Mori M, Sakagami Y, Narita M, Isogai A, Fujino M, Kitada C, Craig R, Clewell D, Suzuki A: Isolation and structure of the bacterial sex pheromone, cAD1, that induces plasmid transfer in Streptococcus faecalis. FEBS Letters 1984, 178: 97-100.

61. Mori M, Tanaka H, Sakagami Y, Isogai A, Fujino M, Kitada C, White BA, An FY, Clewell DIs, Suzuki A: Isolation and structure of the Streptococcus faecalis sex pheromonc, cAM373. FEBS Letters 1986, 206: 69-72.

62. Mori M, Sakagami Y, Ishii $Y$, Isogai A, Kitada C, Fujino M, Adsit JC, Dunny GM, Suzuki A: Structure of CCF10, a peptide sex pheromone which induces conjugative transfer of the Strepiococcus faecalis tetracycline-resistance plasmid, pCF10. Journal of Biological Chemistry 1988, 263: 14,574-14,578.

63. Mori M, Tanaka H, Sakagami $\mathbf{Y}$, Isogai $A$, Fujino $M$, Kitada C, Clewell DB, Suzuki A: Isolation and structure of the sex pheromone inhibitor, IPD1, excreted by Streptococcus faecalis donor strains harboring plasmid pPD1. Journal of Bacteriology 1987 , 169: 1747-1749.

64. Mori M, Isogai A, Sakagami Y, Fujino M, Kitada C, Clewell DB, Suzuki A: Isolation and structure of Streptococcus faecalis sex pheromone inhibitor, iAD1, that is excreted by donor strains harboring plasmid pAD1. Agricultural and Biological Chemistry 1986, 50: 539-541.

65. Kitada C, Fujino M, Mori M, Sakagami $Y$, Isogai A, Suzuki A, Clewell DB, Craig R: Synthesis and structure-activity relationships of Streptococcus faecalis sex pheromones, $\mathrm{CPD} 1$ and $\mathrm{CAD} 1$. In: Izumiya $N$ (ed): Peptide chemistry 1984. Protein Research Foundation, Osaka, 1985, p. 43-48.

66. Clewell DB, An FY, Mori M, Ike Y, Suzuki A: Streptococcus faecalis sex pheromone (cAD1) response: evidence that the peptide inhibitor excreted by pAD1-containing cells may be plasmid determined. Plasmid 1987, 17: 65-68.

67. Youngman PJ: Plasmid vectors for recovering and exploiting $\mathrm{Tn} 917$ transposition in Bacillus and other gram-positives. In: Hardy K (ed): Plasmids: a practical approach. IRL Press, Oxford, 1987, p. 79-103.

68. Ike $\mathrm{Y}$, Clewell DB: Genetic analysis of the pAD1 pheromone response in Streptococcus faecalis, using transposon Tn917 as an insertional mutagen. Journal of Bacteriology 1984, 158: 777-783.
69. Ehrenfeld EE, Clewell DB: Transfer functions of the Streptococcus faecalis plasmid pAD1: organization of plasmid DNA encoding response to sex pheromone. Journal of Bacteriology $1987,169: 3473$ 3481.

70. Weaver KE, Clewell DB: Construction of Enterococcus faecalis pAD1 miniplasmids: identification of a minimal pheromone response regulatory region and evaluation of a novel pheromone-dependent growth in hibition. Plasmid 1989, 22: 106-119.

71. Dunny GM, Funk C, Adisit J: Direct stimulation of the transfer of antibiotic resistance by sex pheromones in Streptococcus faecalis. Plasmid 1981, 6:270278.

72. Christie PJ, Dunny GM: Identification of regions of the Streptococcus faecalis plasmid pCF-10 that encode antibiotic resistance and pheromone response functions. Plasmid 1986, 15: 230-241.

73. Clewell DB, An FY, White BA, Gawron-Burke C: Streptococcus faecalis sex pheromonc (cAM373) also produced by Staphylococcus aureus and identification of a conjugative transposon (Tn918). Journal of Bacteriology 1985, 162: 1212-1220.

74. Clewell DB: Sex pheromones, plasmids, and conjugation in Streptococcus faecalis. In: Halvoson $\mathrm{HO}$, Monroy A (ed): The origin and evolution of sex (MBL lectures in biology, Volume 7). Alan R. Liss, New York 1985, p. 13-28.

75. Ember JA, Hugli TE: Characterization of the human neutrophil response to sex pheromones from Streptococcus faecalis. American Journal of Pathology 1989, 134: 797-805.

76. Sannomiya P, Craig RA, Clewell DB, Suzuki A, Fujino M, Till GO, Marasco WA: Characterization of a new class of Enterococcus faecalis derived neutrophil chemotactic peptides, the sex pheromones. Proceedings of the National Acadcmy of Sciences of the USA 1990, 87: 66-70.

77. Clewell DB, Yagi Y, Dunny G, Schultz S: Characterization of three plasmid DNA molecules in a strain of Streptococcus faecalis. Identification of a plasmid determining erythromycin resistance. Journal of Bacteriology 1974, 117: 283-289.

78. Clewell DB, Yagi Y, Bauer B: Plasmid-determined tetracycline resistance in Streptococcus faecalis. Evidence for gene amplification during growth in the presence of tetracyeline. Proceedings of the National Academy of Sciences of the USA 1975, 72: 1720-1724.

79. Yagi Y, Clewell DB; Plasmid-determined telracycline resistance in Streptococcus faecalis. Tandemly repcated resistance determinants in amplified forms of pAMa1 DNA. Journal of Molecular Biology 1976 , 102: $538-600$.

80. Yagi Y, Clewell DB: Identification and characterization of a small sequence located at two sites on the amplifiable tetracycline resistance plasmid pAM $\alpha 1$ in Streptococcus faecalis. Journal of Bacteriology 1977, 129:400-406.

81. Yagi Y, Clewell D B: Amplification of the tetracycline resistance determinant of plasmid pAM $\alpha 1$ in Streptococcus faecalis: dependence on host recombination machinery. Journal of Bacteriology 1980 , 143: 1070-1072.

82. Rownd R, Miki T, Greenberg J, Luckow V, Miller $J$, Huffman G, Proctor G, Finkelstein M, Easton A, Barton C: Structure, dissociation and amplification of composite $R$ plasmid DNA. In: Mitsuhashi S (ed): Microbial drug resistance. Volume 2. University Park Press, Baltimore, 1979, p. 3-22.

83. Perkins JB, Youngman P: Streptococcus plasmid pAM $\alpha 1$ is a composite of two separable replicons, one of which is closely related to Bacillus plasmid pBC16. Journal of Bacteriology 1983, 155: 607-615. 
84. Clewell DB, Yagi Y, Tomich P: Amplification of pAM $\alpha 1$ in Streptococcus faecalis. In: Mitsuhashi S (ed): Microbial drug resistance. Volume 2. University Park Press, Baltimore, 1979, p. 23-32.

85. Bcrnhard K, Schrempf H, Gocbel W: Bacteriocin and antibiotic resistance plasmids in Bacillus cereus and Bacillus subtilis. Journal of Bacteriology 1978 , 133: 897-903.

86. Bingham AHA, Bruton CJ, Atkinson T: Isolation and partial characterization of four plasmids from antibiotic-resistant thermophilic bacilli. Journal of General Microbiology 1979, 114: 401-408.

87. Polak J, Novick RP: Closcly related plasmids from Staphylococcus auretus and soil bacilli. Plasmid 1982, 7: $152-162$.

88. Banai M, Gonda MA, Ranhand JM, LeBlanc DJ: Streptococcus faecalis $\mathrm{R}$ plasmid $\mathrm{pJH1}$ contains a pAM $\alpha 1 \Delta 1$-like replicon. Journal of Bacteriology 1985, 164: 626-632.

89. Shishido K, Noguchi N, Kim C, Ando T: Isolation of a tetracycline-resistance plasmid excised from a chromosomal DNA sequence in Bacillus subtilis. Plasmid 1983, 10:224-234.

90. Ishiwa H, Shibahara H: New shuttle vectors for Escherichia coli and Bacillus subtilis. III. Nucleotide sequence analysis of tetracycline resistance gene of pAM $\alpha 1$ and ori-177. Japanese Journal of Genetics 1985, 60: $485-498$.

91. Burdett V, Inamine J, Rajagopalan S: Heterogeneity of tetracycline resistance determinants in Streptococcus. Journal of Bacteriology 1982, 149:995-1004.

92. Gawron-Burke C, Clewell DB: A transposon in Streptococcus faecalis with fertility properties. Nature 1982, 300: $281-284$.

93. Christie PJ, Korman RZ, Zahler SA, Adsit JC, Dunny GM: Two conjugation systems associated with Streptococcus faecalis plasmid pCF10, identification of a conjugative transposon that transters between Streptococcus faecalis and Bacillus subtilis. Journal of Bacteriology 1987, 169: 2529-2536.

94. Fitzgerald GF, Clewell DB: A conjugative transposon (Tn919) in Streptococcus sanguis. Infection and Immunity $1985,47: 415-420$.

95. Courvalin $\mathbf{P}$, Carlier $\mathbf{C}$ : Transposable multiple antibiotic resistance in Streptococcus pneumoniae. Molecular and Gencral Genetics 1986, 205: 291-297.

96. Vijayakumar MN, Pricbe SD, Guild WR: Structure of a conjugative element in Streptococcus pneumoniae. Journal of Bacteriology 1986, 166: 978-984.

97. Smith M, Guild WR: Evidence for transposition of the conjugative $R$ determinants of Streplococcus agalactiae B109. In: Schlessinger D (ed): Microbiology - 1982. American Society for Microbiology, Washington, DC, 1982, p. 109-111.

98. Inamine J, Burdett V; Structural organization of a 67-kilobase streptococcal conjugative element mediating multiple antibiotic resistance. Journal of Bacteriology 1985, 161: 620-626.

99. LeBouguenec C, Horaud T, Bieth G, Colimon R, Dauguet C: Translocation of antibiotic resistance markers of a plasmid-free Streptococcus pyogenes (group A) strain into different streptococcal hemolysin plasmids. Molecular and General Genetics 1984,$194 ; 377-387$.

100. Hachler H, Kayser FH, Berger-Bachi B: Homology of a transferable tetracycline resistance determinant of Clostridium difficile with Streptococcus (Enterococcus) faecalis transposon Tn976. Antimicrobial Agents and Chemotherapy 1987, 31: 10331038.

101. Courvalin P, Carlier C: Tn 1545: a conjugative shuttle transposon. Molecular and General Genetics 1987, 206: 259-264.
102. Caillaud F, Courvalin P: Nucleotide sequence of the ends of the conjugative shuttle transposon $\mathrm{Tn}$ 1545. Molecular and General Genetics 1987, 209: 110115.

103. Martin P, Trieu-Cuot $\mathbf{P}$, Courvalin P: Nucleotide sequence of the tet $M$ tetracycline resistance determinant of the streptococcal conjugative shutle transposon Tn1545. Nucleic Acids Research 1986, 14: $7047-7058$.

104. Gawron-Burke C, Clewell DB: Regeneration of insertionally inactivated streptococcal DNA fragments after excision of transposon Tn916 in Escherichia coli: strategy for targeting and cloning of genes from gram-positive bacteria. Journal of Bacteriology 1984, 159: 214-221.

105. Scott JR, Kirchman PA, Caparon MG: An intermediate in transposition of the conjugative trans. poson Tn916. Proceedings of the National Academy of Sciences of the USA 1988, 85: 4809-4813.

106. Wirth R, An FY, Clewell DB: Highly efficient protoplast transformation system for Sireplococcus faecalis and a new Escherichia coli-Streptococcus faecalis shuttle vector, Journal of Bacteriology 1986, 165 : 831-836.

107. Yamamoto M, Jones JM, Senghas E, Gawron-Burke C, Clewell DB: Generation of $\operatorname{Tn} 5$ insertions in streptococcal conjugative transposon Tn976. Applied and Environmental Microbiology 1987, 53: 1069-1072.

108. Senghas $E$, Jones JM, Yamamoto $M$, GawronBurke C, Clewell DB; Genetic organiration of the bacterial conjugative transposon Tn916. Journal of Bacteriology 1988, 170: 245-249.

109. Jones JM, Gawron-Burke C, Flannagan SE, Yamamoto M, Senghas E, Clewell DB: Structural and genetic studies of the conjugative transposon Tn916. In: Ferretti J, Curtiss III R (ed): Sireptococcal genetics. American Society for Microbiology, Washington, DC, 1987 , p. $54-60$.

110. Clewell DB, Flannagan SE, Ike $\mathbf{Y}$, Jones JM, Gawron-Burke C: Sequence analysis of termini of conjugative transposon Tn916. Journal of Bacteriology 1988, 170: 3046-3052.

111. Poyart-Salmeron C, Tricu-Cuot P, Carlier C, Courvalin P: Molecular characterization of two proteins involved in the excision of the conjugative transposon Tn 1545: homologies with other site-specific recombinases. EMBO Journal 1989, 8: 24252433.

112. Sherratt $D: \operatorname{Tn} 3$ and related transposable elements: site-specific recombination and transposition. In: Berg DE, Howe MM (ed): Mobile DNA. American Society for Micrabiology, Washington, DC, 1989, p. 163-184.

113. Shaw J, Clewell DB: Complete nucleotide sequence of macrolide lincosamide-streptogramin $B$. resistance transposon Tn917 in Sireplococcus faecalis. Journal of Bacteriology 1985, 164: 782-796.

114. Perkins J, Youngman PJ: A physical and functional analysis of Tn917, a Streptococcus transposon in the Tn3 family that functions in Bacillus. Plasmid 1984, 12: 119-138.

115. Yagi Y, MeLellan T, Frez W, Clewell D: Characterization of a small plasmid determining resistance to erythromycin, lincomycin and vernamycin $B$ in a strain of Streptococcus sanguis isolated from dental plaque. Antimicrobial Agents and Chemotherapy 1978, 13: 884-887.

116. Horinouchi S, Byeon W-H, Weisblum B: A complex attenuator regulates inducible resistance to macrolides, lincosamides, and streptogramin type B antibiotics in Streptococcus sanguis. Journal of . Bacteriology 1983, 154: 1252-1262. 
117. Murphy E: Transposable clements in gram-positive bacteria. In: Berg DE, Howe MM (ed): Mobile DNA. American Society for Microbiology, Washington, DC, 1989 , p. 269-288.

118. Schmitt $\mathbf{R}$, Altenbuchner $\mathbf{J}$, Wichauer $\mathrm{K}$, Arnold W, Puhler A, Schoff F: Basis of transposition and gene amplification by $\operatorname{Tn} 1721$ and related tetracycline resistance transposons. Cold Spring Harbor Symposia on Quantitative Biology $1981,45: 319-353$.

119. Schoffl F, Arnold W, Puhler A, Altenbuchner J, Schmitt R: The tetracycline resistance transposons Tn1721 and $\operatorname{Tn} 1771$ have three 38 -base-pair repeats and generate 5-base-pair direct repeats. Molecular and General Genetics 1981, 181: 87-94.

120. Lereclus D, Mahillon J, Menou G, Lecadet M: Identification of Tn4430, a transposon of Bacillus thuringiensis functional in Escherichia coli. Molecular and General Genetics 1986, 204: 52-57.

121. Mahillon J, Lereclus D: Structural and functional analysis of Tn4430: identification of an integrase-like protein involved in the cointegrate-resolution process. EMBO Journal 1988, 7:1515-1526.

122. Mahillon J, Seurinck J, Delcour J, Zabeau M: Cloning and nucleotide sequence of different isoIS231 elements and their structural association with the Tn 4430 transposon in Bacillus thuringiensis. Gene 1987, 51: 187-196.

123. Kitts PA, Reed R, Symington L, Burke $M$, Sher* ratt DJ: Transposon-specified site-specific recombination. Proceedings of the National Academy of Sciences of the USA 1982, 79: 46-50.

124. Banai M, LeBlanc DJ: Streptococcus faecalis $\mathrm{R}$ plasmid pJH1 contains an erythromycin resistance transposon ( $\mathrm{Tn} 3871$ ) similar to transposon $\mathrm{Tn} 917$. Journal of Bactcriology 1984, 158: 1172-1174.

125. Rollins LD, Lee LN, LeBlanc DJ: Evidence for a disseminated erythromycin resistance determinani mediated by Tn917-like sequences among group $D$ streptococci isolated from pigs, chickens, and humans. Antimicrobial Agents and Chemotherapy 1985, 27: 439-444.

126. LeBlane DJ, Inamine JM, Lee LN: Broad geographical distribution of homologous crythromycin, kanamycin, and streptomycin resistance determinants among group D streptococci of human and animal origin. Antimicrobial Agents and Chemotherapy $1986,29: 549-555$.

127. Weaver KE, Clewell DB: Transposon Tn917 delivery vectors for mutagenesis in Streptococcus faecalis, In: Ferretti J, Curtiss III R (cd): Streptococcal genetics. American Society for Microbiology, Washington, DC, 1987 , p. 17-21,

128. Patterson JE, Masecar BL, Kauftman CA, Schaberg DR, Hierholzer WJ, Zervos MJ: Gentamicin resistance plasmids of enterococci from diverse geographic areas are heterogeneous. Journal of Infectious Diseases 1988, 158: 212-216.

129. Zervos MK, Mikesell TS, Schaberg DR: Heterogeneity of plasmids determining high-level resistance to gentamicin in clinical isolates of Streptococcus faecalis. Antimicrobial Agents and Chemotherapy 1986, 30: 78-81.

130. LeBlanc DJ, Lee LN, Clewell DB, Behnke D; Broad geographical distribution of a cytotoxin gene mediating beta-hemolysis and bacteriocin activity among Sireptococcus faecalis strains. Infection and Immunity 1983, 40: 1015-1022.

131. Ike Y, Hashimoto $\mathbf{Y}$, Clewell DB: Hemolysin of Streptococcus faecalis subspecies zymogenes contributes to virulence in mice. Infection and Immunity 1984, 45: 528-530.

132. Brock TD, Davic JM: Probable identity of group D hemolysin with bacteriocin. Journal of Bacteriology 1963, 86: 708-712,

133. Basinger SF, Jackson RW: Bacteriocin (hemolysin) of Streptococcus zymogenes. Journal of Bacteriology 1968,96:1895-1902.

134. Ike Y, Clewell DB: High incidence of hemolysin production by Streptococcus faecalis strains associated with human parenteral infections: structure of hemolysin plasmids. In: Ferretti J, Curtiss III R (ed): Streptococcal genetics. American Society for Microbiology, Washington, DC, 1987, p. 159-164.

135. Granato PA, Jackson RW: Bicomponent nature of lysin from Streptococcus zymogenes. Journal of Bacteriology 1969, 100: 865-868.

136. Granato PA, Jackson RW: Characterization of the A component of Streptococcus zymogenes lysin. Journal of Bacteriology 1971, 107: 551-556.

137. Granato PA, Jackson RW: Purification and characterization of the L component of Streptococcus zymogenes lysin. Journal of Bacteriology 1971, 108: 804-808.

138. Ike Y, Clewell DB, Segarra RA, Gilmore MS: Genetic analysis of the $\mathrm{PAD} 1$ hemolysin/bacteriocin determinant in Enterococcus faecalis: Tn917 insertional mutagenesis and cloning. Journal of Bacteriology 1990, 172: 155-163.

139. Murray BE, Church DA, Wanger A, Zscheck K, Levison ME, Ingerman M $\boldsymbol{J}$, Abrutyn E, MederskiSamoraj B: Comparison of two $\beta$-lactamase-producing strains of Streptococcus faecalis. Antimicrobial Agents and Chemotherapy 1986, 30: 861864.

140. Zscheck KK, Hull R, Murray BE: Restriction mapping and hybridization studies of a $\beta$-lactamaseencoding fragment from Streptococcus (Enterococcus) faecalis. Antimicrobial Agents and Chemotherapy 1988, 32: 768-769.

141. Leclereq R, Derlot E, Dubal J, Courvalin P: Plasmid-mediated resistance to vancomycin and teicoplanin in Enterococcus faecium. New England Journal of Medicine 1988, 319:157-161.

142. Shlaes DM, Bouvet A, Devine C, Shlaes JH, AlObied S, Williamson R: Inducible, transferable resistance to vancomycin in Enterococcus faecalis A256. Antimicrobial Agents and Chemotherapy 1989, 33: 198-203. 